\title{
Free recall learning as related to variabllity of within-list meaningfulness
}

LOUIS G. LIPPMAN and JUDITH $A$. CARLSON, Western Washington State College, Bellingham, Wash 98225

Performance in free-recall learning was compared between CVC lists in which the distribution of meaningfulness $(A V)$ about the mean of $50.0 \% A V$ was leptokurtic, platykurtic, or bimodal. Total list acquisition was not affected by differences in $A V$ distribution, but the variability of groups' performance was found to be associated with the range of within-list $A V$.

It has been demonstrated with repeated measures (e.g., McGeoch, 1930) and with independent groups designs (e.g., Dowling \& Braun, 1957) that measures of meaningfulness (AV) and the rate of acquisition are directly related. Since this relationship between $\mathrm{AV}$ and acquisition obtains for mixed lists (e.g., Noble \& McNeely, 1957), it might be inferred that total groups' variability in performance is associated with within-list variability in AV. The present study was a direct test of this inference, i.e., that within-list variability of AV would influence the topography, but not rate, of groups' free-recall learning.

$$
\text { SUBJECTS }
$$

The Ss were 78 introductory psychology students from Westem Washington State College who had no prior experience in learning nonsense material. Participation in an experiment fulfilled a course requirement.

\section{MATERIALS}

Six 10-item lists of CVC trigrams, each having a mean of $50.0 \% \mathrm{AV}$ according to Archer (1960), were constructed according to the following rules: each of the vowels $A$, $E, I, O$, and $U$ appeared in at least one but no more than four items; the letter $Y$ and combinations which formed words were eliminated; one of the 20 consonants was not represented and one was repeated such that the repeated letter appeared in the first and second consonant positions of different trigrams.

Three distributions of AV were represented by two lists each. Lists L (for leptokurtic) had minimal variability of $\mathrm{AV}$ about the mean of $50.0 \%$, such that the AV ranged from $48 \%$ to $52 \%$ inclusive. Specific AV values for the items of each of these lists were: $48,49,50(6), 51,52$ and $48(2), 49(2)$, $50(2), 51(2), 52(2)$. Lists $P$ (for platykurtic) had greater variability in AV since the syllables ranged from $10 \%$ to $90 \%$ AV along an approximately uniform distribution.
Specific AV values of syllables within both $P$ lists were: $10,19,28,37,46,54,63,72,81$, and 90 . Lists B had maximum variability in AV since the syllables ranged from $10 \%$ to 90\% AV in an approximately bimodal distribution. Specific AV values for the items of each of these lists were: $10(2)$, $11(2), 12,88,89(2), 90(2)$ and $10(3), 11$, $12,88,89,90(3)$. The $P$ and $B$ lists were thus matched in terms of the range of $\mathrm{AV}$ but differed in the variance; both of these list conditions, however, resulted in higher range and variance of $A V$ than did $L$ lists.

Each of the syllables was printed in 2-in. block letters on $5 \times 8$ in. index cards. Each $S$ was provided with a response booklet that consisted of $1551 / 2 \times 8 \frac{1}{2}$ in. pages. A stopwatch was used to time trials and stimulus presentation.

\section{PROCEDURE}

Subjects were tested in groups of three to four Ss each. These groups we re assigned to lists by rotation until a total of 13 Ss had learned each of the six lists.

After Ss were seated and provided with response booklets, instructions for free-recall learning were read aloud. Briefly, Ss were instructed that trigrams printed on cards would be exposed for $1 \mathrm{sec}$ each Following presentation of all items, Ss were to write as many items as they could recall within $30 \mathrm{sec}$ onto the first page of their response booklets. Then, the Ss were to turn to the next blank page of the booklet; the cards, which had been shuffled into a different sequence, would be presented again, and another $30-\mathrm{sec}$ recall trial would ensue. The Ss were told that this process of alternate presentation and recall trials would continue "a number of times." The Ss were encouraged to work quickly, but to write legibly.

Each $S$ completed 15 presentation and recall trials, irrespective of his performance. Each S's data were scored for (1) total number of items correct on each trial, and (2) the total number of occasions each item was recalled correctly across all 15 trials.

\section{RESULTS AND DISCUSSION}

Total-List Acquisition

Data from the two lists which represented the three list conditions were pooled. These data were then reduced to five blocks of three trials each. Analysis of variance of these data indicated that performance improved over trials in all groups ( $F=278.76, \mathrm{df}=4 / 300, p<.01)$, but that AV distribution did not affect overall learning or the rate of acquisition (both Fs $<1$ ). Two orthogonal comparisons were also performed using total-list acquisition data. Comparison of performance between Lists $P$ and $B$ tested for the effects of differences in variance with identical range in AV distribution; comparison of total correct responses between List $L$ and Lists $P$ and $B$ combined tested for the effects of differences in both range and variance in AV distribution. Neither of these comparisons was significant (both $F s \leqslant 1.04$ ).

In order to compare immediate retention as related to AV distribution, the number of items correctly recalled on Trial 1 was compared using pooled data for each list condition. Analysis of variance and orthogonal comparisons indicated that Trial 1 performance did not differ significantly between the three list conditions. These results thus indicate that total-list immediate recall and total-list acquisition with repeated trials are not significantly affected by differences in the variability of $A V$.

Variability in Groups' Performance

The mean total occasions each item was recalled correctly was calculated for each item in each of the six lists, and the range and standard deviation were calculated for each of these six distributions of performance scores. Thus, two measures of variability were calculated for each of the two lists which represented the $L, P$, and $B$ distributions of AV. Orthogonal comparisons of Lists $P$ vs $B$ and of Lists $L$ vs $P$ and $B$ combined were performed using each of the variability measures. Differences in standard deviation of performance scores between Lists $P$ and $B(F<1)$ and between Lists $L$ vs $P$ and $B(F=5.73$, df $=1 / 4$, $.05<\mathrm{p}<.10$ ) were not significant. The difference in the range of performance scores between Lists $P$ and $B$ was nonsignificant $(F<1)$, but the range of performance scores on these lists was significantly greater than for List L $(\mathrm{F}=7.84, \mathrm{df}=1 / 4, \mathrm{p}<.05)$.

These results thus indicate that the range (and perhaps overall variability) of a group's performance scores tends to "match" the range of within-list AV. Furthermore, since restriction of range of scores (through sampling bias) can attenuate the value of a correlation coefficient, and if reduction in the range of within-list $A V$ is associated with reduced variability in performance scores, then lists of heterogeneous items (e.g., including CCCs, CVCs, and three-letter words) should permit better prediction of individual item acquisition (Undrwood, 1966) than lists in which the range of AV has been restricted through the use of items which are structurally homogeneous (Lippman \& Kintz, 1968).

REFERENCES

ARCHER, E. J. A retualuation of the 
meaningfulness of all possible CVC trigrams. Psychological Monographs, 1960, 74(10, Whole No. 497).

DOWLING, R. M., \& BRAUN, H. W. Retention and meaningfulness of material. Journal of Experimental Psychology, 1957, 54, 213-217.

LIPPMAN, L. G., \& KINTZ, B. L. Group predictions of item differences of CVC trigrams. Psychonomic Science, 1968, 12, 265-266.

McGEOCH, J. A. The influence of associative value upon the difficulty of non-sense-syllable lists.
Journal of Genetic Psychology, 1930, 37, 421-426.

NOBLE, C. E., \& McNEELY, D. A. The role of meaningfulness $(\mathrm{m})$ in paired-associate verbal learning. Journal of Experimental Psychology, $1957,53,16-22$.

UNDERWOOD, B. J. Individual and group predictions of item difficulty for free leaming. Journal of Experimental Psychology, 1966, 71, 673-679.

\section{Information and meaningfulness needs in sensory deprivation 1}

\section{P. BRUCE LANDON and PETER SUEDFELD, Rutgers, The State University, New Brunswick, N.J. 08903}

To evaluate the relative reinforcement value of unpredictability and meaningfulness in sensory deprivation, $S s$ were allowed to button-press for visual stimuli after $0,1.5$, or $3 \mathrm{~h}$ of darkness and silence. Stimuli were proverbs, the same with words randomly arranged, or the same with letters randomly arranged. Increasing duration led to more pressing, but with no difference among stimuli. Boredom ratings indicated increase with time and low boredom with random words. The susceptibility of these stimuli to active cognitive manipulation may have been the relevant characteristic.

In a series of studies, Jones and his coworkers (see Jones, 1969) made nonmeaningful stimuli available to $S s$ in sensory deprivation. Using light and tone patterns of various levels of fluctuation, complexity, and information (defined in terms of randomness), they found that the last of these was the best predictor of the reinforcement value of the stimuli. Since previous research had indicated that meaningfulness was also reinforcing (Rosenzweig \& Gardner, 1966; Jones, 1969), we designed the present experiment to evaluate the relative importance of these two factors to sensorially deprived Ss. Further, we wanted a parametric manipulation to determine the effects of deprivation duration on pressing for the stimuli.

\section{METHOD}

Sixty-nine students, paid at $\$ 1.50$ per hour, were randomly assigned to nine treatment groups. Each replication was completed before another was begun;group size was equated at six and, after eight nonresponders were eliminated, $54 \mathrm{Ss}$ were used in the major analyses. The deprivation durations were $0,1.5$, and $3 \mathrm{~h}$, with $\mathrm{S}$ lying on a bed in a dark, sound-attenuating chamber. Stimuli consisted of 76 red-on-black slides presenting English proverbs $(\mathrm{P})$, the same with order of words randomized $(W)$, or the same with letter order randomized (L). Meaningfulness decreased and unpredictability (information value) increased in this order. After the appropriate period of deprivation, $S$ was informed that he could obtain stimuli by pressing a button; each press brought a $10-\sec$ exposure, the projector then cycling on to the next slide.

Predeprivation instruments consisted of the Wonderlick Intelligence Test, Form I, and the Sensation Seeking Scale (Zuckerman, Kolin, Price, \& Zoob, 1964; Zuckerman \& Link, 1968). After release, the Effectance Scale (Byrne \& Clore, 1967) was administered.

\section{RESULTS}

Because of skewedness, a nonparametric ANOVA (Wilson, 1956) was used to analyze instrumental responding. Only time in deprivation had an effect, $\chi^{2}=5.78$, $p<.06$ (see Table 1 ). The only other major difference was found on the "boredom" self-rating of the Effectance Scale, with both stimuli and duration having significant effects $[F(2,45)=4.78$ and 4.34 , both $p<.025]$.

There were no pre- or posttest differences between responders and nonresponders. The Sensation Seeking Scale predicted effectance ratings, $r=.36, p<.01$.

\section{DISCUSSION}

In postexperimental interviews, nonrespondents reported that they had believed the instructions, but had not desired to see any stimuli; thus, suspicion $v$
Table 1

Instrumental Responses and Boredom Ratings

\begin{tabular}{lcccc}
\hline & \multicolumn{4}{c}{ Deprivation Duration (Hours) } \\
\cline { 2 - 5 } Series & 0.0 & 1.5 & 3.0 & $\overline{\mathrm{X}}$ \\
\hline \multicolumn{5}{c}{ Mean Responses Per Minute } \\
$\mathrm{P}$ & 0.35 & 2.27 & 1.44 & 1.35 \\
$\mathrm{~W}$ & 0.84 & 1.99 & 1.81 & 1.54 \\
$\mathrm{~L}$ & 1.09 & 2.04 & 2.12 & 1.75 \\
$\overline{\mathrm{X}}$ & 0.76 & 2.10 & 1.79 & 1.55 \\
\multicolumn{5}{c}{ Mean Boredom Rating* } \\
$\mathrm{P}$ & 1.83 & 2.50 & 0.83 & 1.72 \\
$\mathrm{~W}$ & 3.33 & 2.50 & 2.67 & 2.83 \\
$\mathrm{~L}$ & 3.00 & 1.33 & 1.67 & 1.83 \\
$\overline{\mathrm{X}}$ & 2.72 & 2.11 & 1.56 & 2.13 \\
\hline * 0 (“Extremely & bored") & to 4 ("Not at all \\
bored") & \multicolumn{5}{c}{}
\end{tabular}

demand characteristics do not seem to be responsible for the difference. Instrumental response rate, while indicating that the stimuli increase in reinforcement value as time in deprivation increases from 0 , did not show whether information or meaningfulness was the more relevant characteristic.

Boredom ratings, reflecting linear increase with duration, also were lower for Series W than for either Series P or L. Thus, the moderately meaningful and moderately unpredictable stimuli led to less boredom. Since this series was the most capable of being cognitively manipulated for a meaningful outcome, the result supports theories that emphasize the need for active structuring of the environment (e.g., Fiske \& Maddi, 1961; Gibson, 1966). To strengthen this inference, it would be desirable to conduct an experiment in which Ss have a choice among $P, W$, and $L$ stimuli and then to compare results within as well as across Ss.

\section{REFERENCES}

BYRNE, D., \& CLORE, J. L. Effectance arousal and attraction. Journal of Personality \& Social Psychology, 1967, 6, (Monograph 6, Whole No. 638).

FISKE, D. W., \& MADDI, S. R. Functions of varied experience. Homewood, Ill.: Dorsey, 1961.

GIBSON, J. J. The senses considered as perceptual systems. New York: Houghton-Mifflin, 1966.

JONES A. Stimulus-seeking behavior. In J. P. Zubek (Ed.), Sensory deprivation: Fifteen years of research. New York: Appleton-Century-Crofts, 1969. Pp. 167-206.

ROSENZWEIG, N., \& GARDNER, L. The role of input relevance in sensory isolation. American Journal of Psychology, 1966, 122, 920-927.

WILSON, K. V. A distribution-free test of analy sis of variance hypotheses. Psychological Bulletin, 1956,53, 96-101.

ZUCKERMAN, M., KOLIN, E. A., PRICE, L., \& ZOOB, I. Development of a sensation seeking scale. Journal of Consulting Psychology, 1964, 28, 477-482.

ZUCKERMAN, M., \& LINK, M. Construct validity for the Sensation Seeking Scale. Journal of Consulting \& Clinical Psychology, 1968, 32, 420-426.

NOTE

1. This research was financed by a grant from the Rutgers University Research Council to the second author. 